\title{
ENTRE LA INFORMACIÓN Y LA DESINFORMACIÓN: LOS JUICIOS PARALELOS Y SU INFLUENCIA EN LAS DECISIONES JUDICIALES
}

Edwar Álvarez Yrala*

Recibido: 26.09 .2014

Aprobado: 03.10.2014

\section{RESUMEN}

El autor enfoca su análisis en cómo la formación de juicios paralelos por parte de los órganos de prensa en la sociedad no solo afecta la imparcialidad en los jueces, sino también puede suponer un irregular ejercicio de las libertades comunicativas lesivas de los derechos sustantivos y procesales del imputado. A partir de allí formula su oposición a posturas como la despenalización de los delitos contra el honor, porque no son adecuadas para nuestra sociedad.

\section{PALABRAS CLAVE}

Juicios paralelos - Libertad de expresión - Rectificación - Presunción de Inocencia - Imparcialidad judicial.

\section{ABSTRACT}

The author focuses his analysis on how the formation of parallel trials by the media in our society not only affects judge's impartiality, but can also entail an irregular exercise of the freedoms of communication, damaging substantive and procedural rights of accused. Based on such insight, the author formulates his opposition to those who favor the decriminalization of offenses against honor because they are not suitable for our society.

\section{KEY WORDS}

Parallel trials - Freedom of expression - Disclaimer - Presumption of Innocence - Impartial Judiciary.

\section{INTRODUCCIÓN}

Thomas Jefferson -ex presidente de los Estados Unidos de América- decía que "nuestra libertad depende de nuestra libertad de prensa" y que, por eso, esta era ilimitada; sin embargo, actualmente si bien la libertad de prensa es un derecho fundamental, no por ello se le reconoce como un derecho absoluto, sino que tiene ciertas restricciones; por ejemplo, no puede ser ejercida desconociendo otros derechos tan importantes como el honor, por ejemplo. En ese contexto, mediante el presente artículo exponemos la situación de tensión que existe entre las libertades de comunicación y las garantías básicas que componen un debido proceso cuando un caso judicial (sobre todo, en el ámbito penal) es sometido al tratamiento de los medios de comunicación.

Es innegable que vivimos en tiempos de una sociedad mediatizada, en la que el protagonismo de los medios de prensa no se reduce a los espacios po-

\footnotetext{
* Abogado y Magister en Ciencias Penales por la Universidad San Martín de Porres. Profesor del Área de Ciencias Penales de las Facultades de Derecho de la Universidad Femenina Sagrado Corazón y la Universidad de San Martín de Porres. Ha sido Juez Penal Provisional en lo Penal. Es autor de diversas publicaciones de la especialidad.
} 
líticos, sino que se extiende a todos los espacios sociales, más aún cuando el desarrollo de las nuevas tecnologías de información amplían su difusión en forma desmedida, de allí se deriva el empoderamiento del que goza el llamado cuarto poder, el poder que tiene para decidir sobre las orientaciones de las personas y sus actividades en sociedad.

Actualmente, por ejemplo, somos testigos que frente a la situación de inseguridad ciudadana y la revelación de casos de corrupción, discutir la imposición de la medida de coerción de prisión preventiva no pasa ya por verificar la concurrencia de los presupuestos establecidos en la norma procesal (artículo 268 del Código Procesal Penal), sino el análisis se reduce al tratamiento del caso en los medios de comunicación -televisión, radio, prensa escrita-; prueba de ello es que los actores del proceso penal (llámense, fiscales, procuradores), no exponen sus argumentos en los estrados judiciales, sino en los noticieros, programas políticos o en entrevistas periodísticas. ¿Y cuál es la respuesta de los jueces peruanos frente a esto? Éstos -débiles, timoratos- ceden a la presión, "se lavan las manos" y deciden que en todo caso sea el juez superior el que resuelva su situación, toman su decisión en función de lo que espera y quiere el público: ver autoridades presas, aunque para el caso no concurran los presupuestos legales de la prisión preventiva como medida excepcional. $Y$ es más, esto no solo influye en los jueces que deciden, sino también en los órganos de control (vale decir, la OCMA) porque apenas se exhibe una decisión socialmente incómoda, los jueces son sometidos a procesos disciplinarios, y cualquier otro mecanismo de defensa que utilicen las personas sometidas a proceso se ve debilitado porque ningún juez actuará conforme a derecho, sino que -intimidadorechazará, más aún cuando no se cuenta con el respaldo del presidente del Poder Judicial que (en lugar de apoyar a los jueces) termina empujándolos hacia su "destitución" o, como ya ha pasado, su "reubicación"1 y afectando la independencia de los jueces ${ }^{2}$. Por estas razones, se hace importante reflexionar sobre la problemática de los juicios mediáticos y su afectación a los derechos del imputado.

\section{LAS LIBERTADES COMUNICATIVAS Y SUS LIMITACIONES}

La Corte Interamericana de Derechos Humanos destacó que los periodistas ejercen las libertades comunicativas por cuanto:

“... el ejercicio del periodismo profesional no puede ser diferenciado de la libertad de expresión, por el contrario, ambas cosas están evidentemente imbricadas, pues el periodista profesional no es, ni puede ser, otra cosa que una persona que ha decidido ejercer la libertad de expresión de modo continuo, estable y remunerado ..."3.

\section{a. Distinción entre libertades de expresión e informa- ción}

Es importante precisar que si bien las libertades de expresión e información tienen por objeto cautelar la libre comunicación, son derechos distintos. La libertad de expresión tiene por objeto la difusión del pensamiento, la opinión, la idea o el juicio de valor. En cambio, en el ejercicio de la libertad de información se dan a conocer hechos o datos objetivos, no opiniones.

Al respecto, el Tribunal Constitucional ha anotado que:

“... [a]un cuando históricamente la libertad de información haya surgido en el seno de la libertad de expresión, y a veces sea difícil diferenciar la una de la otra, el referido inciso 4) del artículo $2^{\circ}$ de la Constitución las ha reconocido de manera independiente, esto es, como dos dere-

1 Los jueces de la Sala Penal Nacional que dispusieron la variación de prisión preventiva a comparecencia a los procesados por el caso MOVADEF fueron removidos de sus puestos y reubicados. Al respecto, véase: http://www.larepublica. pe/08-08-2014/ollanta-humala-saluda-cambio-de-jueces-que-liberaron-a-cupula-de-movadef; y http://www.larepublica.pe/08-08-2014/pj-cambia-a-jueces-que-excarcelaron-a-cupula-del-movadef

2 A raíz de las querellas contra periodistas y medios de comunicación formuladas por Rodolfo Orellana, el Presidente del Poder Judicial no solo exhortó a los jueces que califiquen correctamente las querellas, sino que además posteriormente emitió una directiva señalando que los jueces deberían "revisar exhaustivamente" las querellas planteadas. Al respecto, vide: http://elcomercio.pe/politica/justicia/enrique-mendoza-poder-judicial-pide-jueces-verificar-demandas-contra-periodistas-noticia-1737460.

3 Corte Interamericana de Derechos Humanos. Opinión Consultiva OC-5/85, La colegiación obligatoria de periodistas (arts. 13 y 29 de la Convención Americana sobre Derechos Humanos), de 13 de noviembre de 1985. Párrafo 74. 
chos distintos y, por tanto, cada uno con un objeto de protección distinto.

(...)

Así, mientras que con la libertad de expresión se garantiza la difusión del pensamiento, la opinión o los juicios de valor que cualquier persona pueda emitir, la libertad de información garantiza el acceso, la búsqueda y la difusión de hechos noticiosos 0 , en otros términos, la información veraz. Por su propia naturaleza, los juicios de valor, las opiniones, los pensamientos o las ideas que cada persona pueda tener son de naturaleza estrictamente subjetivas $y$, por tanto, no pueden ser sometidos a un test de veracidad; a diferencia de lo que sucede con los hechos noticiosos, que, por su misma naturaleza de datos objetivos y contrastables, sí lo pueden ser" (énfasis agregado).

No obstante, estos derechos no son absolutos, sino más bien, están limitados por el respeto a los demás derechos fundamentales y a los valores constitucionales de relevancia. Por ello, a continuación veremos cómo un mal uso de estos derechos -0, en algunos casos, el desconocimiento que éstos tienen límites- genera afectaciones a otros derechos importantes como la presunción de inocencia y el derecho al honor.
3. EL POPULISMO MEDIÁTICO Y LA AFECTACIÓN A LA PRESUNCIÓN DE INOCENCIA

En el sistema internacional de protección de los derechos humanos, el derecho a la presunción de inocencia aparece considerado en el artículo 11.1 de la Declaración Universal de los Derechos Humanos, en el sentido que "Toda persona acusada de delito tiene derecho a que se presuma su inocencia mientras no se pruebe su culpabilidad, conforme a la ley y en juicio público en el que se le hayan asegurado todas las garantías necesarias para su defensa". De igual modo, el citado derecho es enfocado en el artículo 14.2 del Pacto Internacional de Derechos Civiles y Políticos y el artículo 8.2 de la Convención Americana sobre Derechos Humanos. En relación con esta última, “... la Corte ha afirmado que en el principio de presunción de inocencia subyace el propósito de las garantías judiciales, al afirmar la idea de que una persona es inocente hasta que su culpabilidad es demostrada"4.

En concordancia con estos instrumentos internacionales, el artículo 2, inciso 24 de la Constitución establece que "Toda persona es considerada inocente mientras no se haya declarado judicialmente su responsabilidad".

Así, la presunción de inocencia se erige en una presunción iuris tántum, que implica que:

"a todo procesado se le considera inocente mien- tras no se pruebe su culpabilidad: vale decir, hasta que no se exhiba prueba en contrario. Rige desde el momento en que se imputa a alguien la comisión de un delito, quedando el acusado en condición de sospechoso durante toda la tramitación del proceso, hasta que se expida la sentencia definitiva", por lo que "la presunción de inocencia se mantiene 'viva' en el proceso penal siempre que no exista una sentencia judicial que, como corolario del cauce investigatorio llevado a cabo con las garantías inherentes al debido proceso, logre desvirtuarla"s.

Al respecto, Tiedemann señala que el principio de presunción de inocencia determina el comportamiento de los órganos de persecución penal frente a la opinión pública y los medios de comunicación ${ }^{6}$.

No obstante lo afirmado, los medios de prensa por lo general desconocen en la práctica este importante derecho, por cuanto realizan afirmaciones anticipadas generando juicios paralelos a los juicios llevados en los cauces del Poder Judicial.

Al respecto, es de notar que la publicidad de la justicia es una garantía del funcionamiento del Poder Judicial en una sociedad democrática, orientada a fortalecer la confianza pública, así como la responsabilidad de los órganos de administración de justicia, 
y esto es diferente a la publicidad de espectáculo, que genera graves riesgos para todos los participantes, y en especial al indiciado o imputado, que se ve expuesto a un juicio anticipado e incluso a una precondena en los medios de comunicación? ${ }^{7}$.

No hay que confundir los roles que cumplen los órganos jurisdiccionales y los medios de prensa. Los primeros llevan a cabo juicios con la única finalidad de aplicar la ley y restablecer el derecho, mientras que la crónica judicial se orienta, como toda actividad periodística, a formar estados de opinión.

Con esto no estamos tratando de cuestionar o vetar que se hagan las investigaciones periodísticas ni tampoco dar pautas a la prensa de cómo presentar el hecho delictivo, sino que simplemente afirmamos que los órganos de prensa no forman parte de las instituciones públicas a las que el Estado ha encomendado la persecución de delitos. En resumen, los periodistas no pueden suplantar a los jueces al momento de determinar la inocencia o culpabilidad de las personas o adoptar medidas que limiten derechos individuales o patrimoniales.
Por ejemplo, esta distorsión del rol de la prensa formando juicios paralelos genera que en el nuevo modelo procesal se afecta, adicionalmente, el principio de objetividad que debe guiar la actuación del representante del Ministerio Público ${ }^{8}$, ya que desde un principio se convierte en acusador, en parte persecutora, ya no le interesa recabar elementos de cargo y de descargo, sino solo los primeros, y con ello también se afecta la igualdad de armas.

\section{LoS JUICIOS PARALELOS Y LAS AFECTACIONES AL HONOR DE LOS PROCESADOS}

El honor ha sido entendido tradicionalmente en una doble dimensión: como honor interno o autoestima y como honor externo o heteroestima. Al respecto, la Corte Interamericana de Derechos Humanos ha aseverado:

Por un lado, "el derecho a la honra se relaciona con la estima y valía propia, mientras que la reputación se refiere a la opinión que otros tienen de una persona"9.

En la misma línea, el Tribunal Constitucional ha sostenido que:
"La Constitución se refiere en su artículo 2, inciso 7, al derecho fundamental de toda persona "al honor y la buena reputación [...]". De este modo, la Constitución hace referencia a dos dimensiones de protección de la dignidad humana, la primera referida a la persona en tanto que individuo dotado de inmunidad frente a cualquier agresión a su autoestima y su dignidad objetivada como ser libre que se relaciona cotidianamente con sus semejantes" 10 .

En el mismo sentido, la Corte Suprema ha establecido en el Acuerdo Plenario $N^{\circ}$ 3-2006/CJ116:

"El honor es un concepto jurídico ciertamente indeterminado y variable, cuya delimitación depende de las normas, valores e ideas sociales vigentes en cada momento histórico, pero que en todo caso, desde una perspectiva objetiva, aluden a la suma de cualidades que se atribuyen a la persona y que son necesarias para el cumplimiento de los roles específicos que se le encomiendan. Desde un sentido subjetivo el honor importa la conciencia y el sentimiento que tiene la

Cfr. AA.VV (2012). La presunción de inocencia y los juicios paralelos. Madrid: La Ley, p. 46.

"Artículo IV. Titular de la acción penal

(...C)

2. El Ministerio Público está obligado a actuar con objetividad, indagando los hechos constitutivos de delito, los que determinen y acrediten la responsabilidad o inocencia del imputado. Con esta finalidad conduce y controla jurídicamente los actos de investigación que realiza la Policía Nacional".

9 Corte IDH. Caso Tristán Donoso Vs. Panamá. Excepción Preliminar, Fondo, Reparaciones y Costas. Sentencia de 27 de enero de 2009 Serie C No. 193, párr. 57. Ver, además, Corte Constitucional de Colombia. Sentencia sobre la acción de tutela № T-367/93, del 3 de setiembre de 1993. En: Gaceta de la Corte Constitucional. Bogotá: 1993, Tomo 9, p. 309.

10 STC. Exp. 4099-2005-AA/TC. Caso Yovana Del Carmen Gálvez Berrio, Fundamento Jurídico 7. Criterio similar ha sido establecido recientemente, véase RTC. Exp. N 03696-2011-PA/TC. Caso Southern Perú Cooper Corporation, Fundamento Jurídico 4. 
persona de su propia valía y prestigio; reputación y la propia estimación son sus dos elementos constitutivos (...)" (cursivas del original $)^{11}$.

Ahora bien, tanto el honor interno como externo se ven comprometidos cuando un caso es sometido al tratamiento mediático, en tanto que la presentación de una persona como culpable ante la sociedad -a través de los medios de prensa- lo estigmatiza, además que genera un prejuicio en los magistrados.

Si bien es cierto que el imputado tiene derecho a un proceso público (reservado para la fase de juzgamiento), no podemos desconocer que para la población estar inmerso en un proceso penal -en la mayoría de las ocasiones- proyecta una imagen negativa, que afecta marcadamente el honor y la honra de los procesados.

\section{LA RECTIFICACIÓN COMO REME- DIO PROCESAL PERO INSUFICIENTE}

\section{b. Contenido del derecho a la rectificación}

El derecho fundamental a la rectificación está reconocido en el artículo $2^{\circ}$ inciso 7) in fine de la Constitución, en los siguientes términos:

“... Toda persona afectada por afirmaciones inexactas o agraviada en cualquier medio de comunicación social tiene derecho a que éste se rectifique en forma gratuita, inmediata y proporcional, sin perjuicio de las responsabilidades de ley".

El Tribunal Constitucional ha señalado que la rectificación es un derecho fundamental que, según lo expresado en el fundamento 5.a de la sentencia emitida en el Expediente $N^{\circ}$ 082998-AA/TC -que tiene la calidad de precedente vinculante-, está referido a lo siguiente:

La obligación de rectificar informaciones inexactas 0 agraviantes al honor o a la buena reputación difundidas por cualquier medio de comunicación social, tiene por finalidad, a la par de contribuir con una correcta formación de la opinión pública libre, el de corregir informaciones sobre hechos inexactos que hayan sido propalados mediante el ejercicio de la libertad de información, esto es, informaciones cuyo carácter material permita determinar que se trata de informaciones no veraces, o que hayan sido formuladas como consecuencia de no observarse una conducta razonablemente diligente para agenciarse de los hechos noticiosos que podrían ser objeto de información.

La rectificación, como derecho constitucional, se viola en tres supuestos:

-El afectado presenta su carta rectificatoria y no es publicada

-El medio de comunicación publica la carta pero no se rectifica

-El medio de comunicación publica la carta y añade agravios $y$, antes bien, se ratifica en la información lesiva del honor expuesta primigeniamente.

Ciertamente, existe un mecanismo constitucional que sirve para proteger el honor frente a informaciones falsas o inexactas, pero está claro que este medio resulta siendo insuficiente, no solo en cuanto al contenido de la información, porque el daño está hecho, ya se causó y es irreparable, no se puede retroceder el tiempo para evitar la información que daña el honor. Por un lado, la sociedad ya formó opinión sobre el tema (el proceso penal continúa sobre la base de la información distorsionada difundida en los medios de prensa, aun cuando la información propalada sea corregida), $y$, por otro lado, el juez se ve influenciado por esta situación, por lo que muchas veces en el camino, entre la afirmación falsa y la rectificación, ya se produjo la lesión a un derecho -al honor inicialmente $y$, cuando llega a las instancias judiciales, la afectación a las garantías del debido proceso-.

\section{REFLEXIÓN SOBRE LA NO DESPE- NALIZACIÓN DE LOS DELITOS CON- TRA EL HONOR}

Muchas voces han propuesto que los delitos contra el honor -injuria, calumnia y difamaciónsean sustraídos del sistema de justicia penal y llevados a la vía civil.

11 Acuerdo Plenario $N^{\circ} 3-2006 /$ CJ-116. Delitos contra el honor personal y derecho constitucional a la libertad de expression y de información, del 13 de octubre de 2006, Fundamento Jurídico 6. 
Sin embargo, estamos en oposición de esta propuesta, porque cuando no hay prensa profesional y objetiva (y, como la nuestra, que más bien suele responder a intereses de grupo) no puede operar la despenalización de los delitos contra el honor, porque se relega la protección de un bien jurídico como el honor, lo cual es propio de los modelos liberales donde todo se resuelve con dinero, pero no de un modelo constitucional como el nuestro.

\section{Conclusiones}

Las libertades de expresión e información constituyen los cimientos de toda sociedad democrática; sin embargo -a pesar de su trascendencia- no se erigen en derechos absolutos o ilimitados, sino que más bien tienen restricciones, como el respeto a otros derechos o valores constitucionales, como el honor, la presunción de inocencia o la imparcialidad judicial.

Ciertamente, en ejercicio de estas libertades comunicativas, los periodistas realizan afirmaciones sobre los procesos penales en marcha, formando juicios paralelos que muchas veces colisionan con los derechos a la presunción de inocencia y el honor de los imputados, distorsionando además los roles de la justicia penal y de los órganos de prensa, ya que éstos buscan noticias, mientras los jueces buscan determinar responsabilidades penales en un proceso.
No basta con que se respeten principios propios del proceso penal para garantizar un juicio justo sino que además quien juzgue a la persona debe reunir ciertos requisitos que garanticen una decisión justa (imparcialidad o independencia), además que debe garantizarse el proceso en condiciones de igualdad y sin prejuicios. Sin embargo, esto no es posible cuando el tratamiento mediático del caso genera un proceso irregular y violaciones a los derechos del sujeto pasivo del proceso penal, por lo que se debe regular estas situaciones, empezando por no despenalizar los delitos contra el honor y remarcar el carácter insuficiente del derecho de rectificación, los mismos que son remedios posteriores -en el primer caso- y parciales en el segundo. 